\title{
MAKALAH TENTANG BOLA VOLI
}

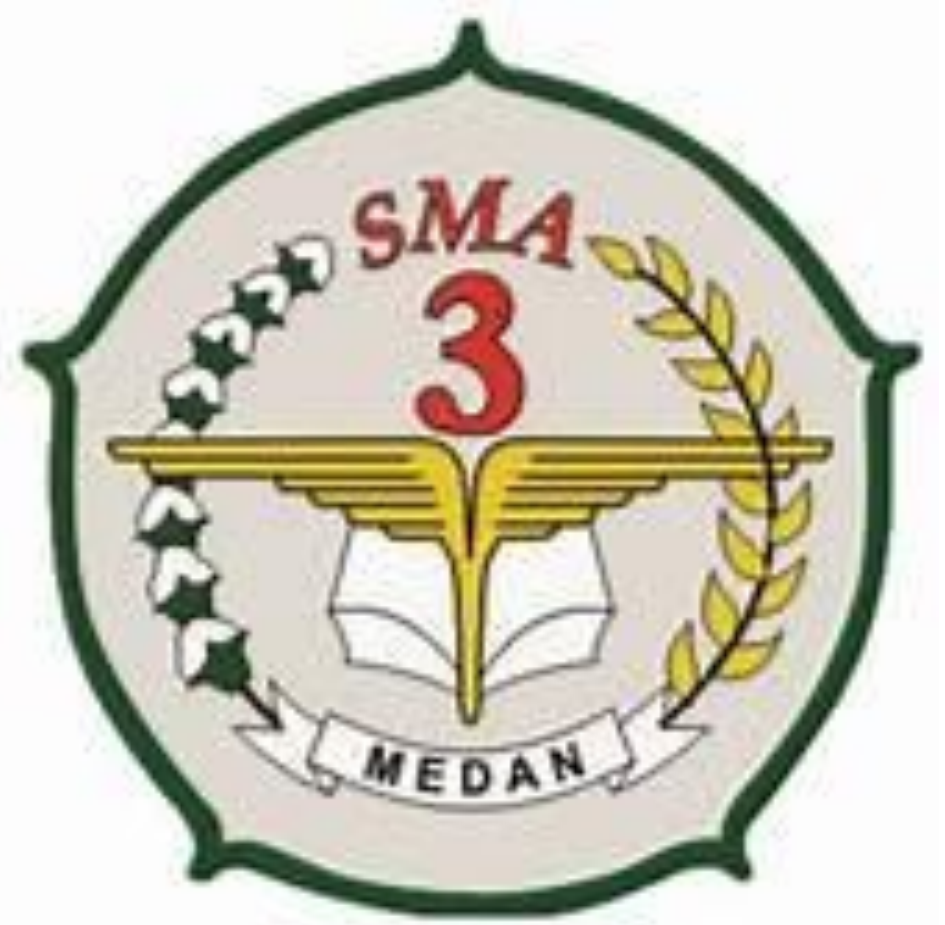

DISUSUN OLEH:

NAMA : CINDY FAZILA

KELAS : X MIA 3

SMA NEGERI 3 MEDAN 


\title{
BAB I
}

\begin{abstract}
ABSTRAK
Dalam makalah ini, penulis membahas tentang sejarah perkembangan olahraga Bola Voli, pengertian olahraga Bola Voli, tehnik yang digunakan dalam olahraga Bola Voli, serta masih banyak pembahasan lainya yang disajikan dalam bentuk makalah. Makalah ini disusun agar para pembaca bisa menambah wawasan serta memperluas ilmu pengetahuan yang ada mengenai Bola Voli.

Penulis juga tidak lupa mengucapkan banyak terima kasih pada rekan-rekan satu tim yang sudah membantu serta dari berbagai pihak lain yang telah membantu penulis dalam penyusunan makalah ini sehingga makalah ini dapat terselesaikan dengan baik serta tepat pada waktunya.

Penulis menyadari bahwa masih banyak kekurangan yang mendasar pada makalah ini. Oleh karena itu penyusun mengundang pembaca untuk memberikan saran serta kritik yang dapat membangun untuk dapat memperbaiki tugas makalah selanjutnya. Dan semoga makalah ini bisa bermanfaat untuk para pembaca dan memperluas wawasan mengenai Bola Voli serta seluk beluknya. Dan tidak lupa permohonan maaf dari penulis apabila terdapat kekurangan dan kesalahan dalam bentuk apapun yang terdapat dalam makalah ini.
\end{abstract}

\section{PENDAHALUAN}

PermainanBOLA voli diciptakan oleh William G. Morgan seorang Instruktur pendidikan jasmani (Director of Phsycal Education) di YMCA pada tanggal 9 Februari 1895, di Holyoke, Massachusetts (Amerika Serikat). Beliau dilahirkan di Lockport, New York pada tahun 1870, dan meninggal pada tahun 1942.

YMCA (Young Men's Christian Association) merupakan sebuah organisasi yang didedikasikan untuk mengajarkan ajaran-ajaran pokok umat Kristen kepada para pemuda, seperti yang telah diajarkan oleh Yesus. Organisasi ini didirikan pada tanggal 6 Juni 1884 di London, Inggris oleh George William. Setelah bertemu dengan James Naismith (seorang pencipta olahraga bola basket yang lahir pada tanggal 6 November 1861, dan meninggal pada tanggal 28 November 1939), Morgan menciptakan sebuah olahraga baru yang bernama 
Mintonette. Sama halnya dengan James Naismith, William G. Morgan juga mendedikasikan hidupnya sebagai seorang instruktur pendidikan jasmani. William G.

Morgan yang juga merupakan lulusan Springfield College of YMCA, menciptakan permainan Mintonette ini empat tahun setelah diciptakannya olahraga permainan basketball oleh James Naismith. Olahraga permainan Mintonette sebenarnya merupakan sebuah permainan yang diciptakan dengan mengkombinasikan beberapa jenis permainan. Tepatnya, permainan Mintonette diciptakan dengan mengadopsi empat macam karakter olahraga permainan menjadi satu, yaituBOLA basket, baseball, tenis, dan yang terakhir adalah bola tangan (handball). Pada awalnya, permainan ini diciptakan khusus bagi anggota YMCA yang sudah tidak berusia muda lagi, sehingga permainan ini-pun dibuat tidak seaktif permainan bola basket.

Nama permainan in semula disebut "Minonette" yang hampir serupa dengan permainan badminton. Jumlah pemain di sini tak terbatas sesuai dengan tujuan semula yakni untuk mengembangkan kesegaran jasmani para buruh di samping bersenam secara missal. William G. Morgan kemudian melanjutkan idenya untuk mengembangkan permainan tersebut agar mencapai cabang olah raga yang dipertandingkan.

Nama permainan kemudian menjadi "volley ball yang artinya kurang lebih mem-volibola pada pada tahun 1896, pada demonstrasi pertandingan pertamanya di International YMCA Training School. Pada awal tahun 1896 tersebut, Dr. Luther Halsey Gulick (Director of the Professional Physical Education Training School sekaligus sebagai Executive Director of Department of Physical Education of the International Committee of YMCA) mengundang dan meminta Morgan untuk mendemonstrasikan permainan baru yang telah ia ciptakan di stadion kampus yang baru. Pada sebuah konferensi yang bertempat di kampus YMCA, Springfield tersebut juga dihadiri oleh seluruh instruktur pendidikan jasmani.

Dalam kesempatan tersebut, Morgan membawa dua tim yang pada masing-masing tim beranggotakan lima orang. Dalam kesempatan itu, Morgan juga menjelaskan bahwa permainan tersebut adalah permainan yang dapat dimainkan di dalam maupun di luar ruangan dengan sangat leluasa. Dan menurut penjelasannya pada saat itu, permainan ini dapat juga dimainkan oleh banyak pemain. Tidak ada batasan jumlah pemain yang menjadi standar dalam permainan tersebut. Sedangkan sasaran dari permainan ini adalah mempertahankanBOLA agar tetap bergerak melewati net yang tinggi, dari satu wilayah ke wilayah lain (wilayah lawan). 
Tahun 1922 YMCA berhasil mengadakan kejuaraan nasional bola voli di Negara Amerika Serikat. Pada saat perang dunia I tentara-tenatra sekutu menyebarluaskan permainan ini ke Negara -negara Asia dan Eropa terutama negarea Jepang, Cina, India, Filipina, Perancis, Rusia, Estonia, Latvia, Ceko-slovakia, Rumania, Yugoslavia dan Jerman.

Dalam perang dunia II permainan ini tersebar luas di seluruh dunia terutama di Eropa dan Asia. Setelah perang dunia II prestasi dan popularitas bola voli di USA menurun, sedang di Negara lain terutama Eropa Timur dan Asia berkembang sangat cepat dan massal.

Mengingat turnamen bola voli yang pertama (1947) di Polandia pesertanya cukup banyak, maka pada tahun 1948 I.V.B.F (international volley ball federation) didirikan yang beranggota 15 negara.

Indonesia mengenal permainanBOLA voli sejak tahun 1982 pada zaman penjajahan Belanda. Guru-guru pendidikan jasmani didatangkan dari negeri Belanda untuk mengembangkan olahraga umumnya dan bola voli khususnya. Di samping guru-guru pendidikan jasmani, tentara Belanda banyak andilnya dalam pengembangan permainan bola voli di Indonesia, terutama dengan bermain di asrama-asrama, di lapangan terbuka dan mengadakan pertandingan antar kompeni-kompeni Belanda sendiri.

PermainanBOLA voli di Indonesia sangat pesat di seluruh lapisan mayarakat, sehingga timbul klub-klub di kota besar di seluruh Indonesia. Dengan dasar itulah maka pada tanggal 22 januari 1955 PBVSI (persatuan bola voli seluruh indonesia) didirikan di Jakarta bersamaan dengan kejuaraan nasional yang pertama.

PBVSI sejak itu aktif mengembangkan kegiatan-kegiatan baik ke dalm maupun ke luar negeri sampai sekarang. Perkembangan permainan bola voli sangat menonjol saat menjelang Asian Games IV 1962 dan Ganefo I 1963 di Jakarta, baik untuk pria maupun untuk wanitanya.

Pertandingan bola voli masuk acara resmi dalam PON II 1951 di Jakarta dan POM I di Yogyakarta tahun 1951. setelah tahun 1962 perkembangan bnola voli seperti jamur tumbuh di musim hujan banyaknya klub-klub bola voli di seluruh pelosok tanah air.

Hal ini terbukti pula dengan data-data peserta pertandingan dalam kejuaran nasional. PON dan pesta-pesta olahraga lain, di mana angka menunjukkan peningkatan jumlahnya.BOLEH dikatakan sampai saat ini permainan bola voli di Indonesia menduduki tempat ketiga setelah sepak bola dan bulu tangkis. 
Untuk pertama kalinya dalam sejarah perbolavolian Indonesia, PBVSI telah dapat mengirimkan tim bola voli yunior Indonesia ke kejuaraan Dunia di Athena Yunani yang berlangsung dari tanggal 3-12 september 1989. tim bola voli yunior putra Indonesia ini dilatih oleh Yano Hadian dengan dibantu oleh trainer Kanwar, serta pelatih dari Jepang Hideto Nishioka, sedangkan pelatih fisik diserahkan kepada Engkos Kosasih dari bidang kepelatihan PKON (pusat kesehatan olahraga nasional) KANTOR MENPORA. Dalam kejuaraan dunia bola voli putra tersebut, sebagai juaranya adalah :

1. Uni Sovyet

2. Jepang

3. Brazil

4. Bulagaria

5. Kuba

6. Yunani

7. Polandia

Sedangkan Indonesia sendiri baru dapat menduduki urutan ke 15.

Dalam periode di bawah pimpinan ketua Umum PBVSI Jendral (Pol) Drs. Mochamad Sanusi, perbolavolian makin meningkat baik dari jumlahnya perkumpulan yang ada maupun dari lancarnya system kompetisi yang berlangsung, sampai dengan kegiatan yang dilakukan baik di dalam maupun di luar negeri.

\section{RUMUSAN MASALAH}

Adanya permainan bola voli yang sering dimainkan maka menimbulkan pertanyaan diantaranya :

1. Apa pengertian dan peraturan dalam permainan bola voli

2. Apa teknik dasar dalam permainan bola voli

3. Apa yang dimaksud smash dan bagaimana cara melakukan smash dalam permainan bola voli 
4. Apa yang dimaksud blok(bendungan) dan bagaimana cara melakukan block / bendungan

\section{TUJUAN MAKALAH}

Tujuan penyusunan makalah ini adalah :

1. Memenuhi salah satu tugas mata pelajaran

2. Mengetahui hal mengenai bola voli

\section{BAB II}

\section{PEMBAHASAN}

\section{KAJIAN TEORI}

1. Pengertian

Bola voli adalah olahraga permainan yang dimainkan oleh dua grup berlawanan. Masingmasing grup memiliki enam orang pemain. Terdapat pula variasi permainan bola voli pantai yang masing-masing grup hanya memiliki dua orang pemain.

Peraturan Permainan

Untuk dapat memainkan permainan bola voli tidak dapat dilaksanakan denga asal-asalan begitu saja, namun harus mentaati beberapa peraturan yang telah di tetapkan seperti posisi, cara bermainan, lapangan, dan masih banyak lagi.

\section{Lapangan}

Lapangan permainan bola voli berbentuk persegi panjang dengan ukuran panjang $18 \mathrm{~m}$ dan lebar $9 \mathrm{~m}$, semua garis batas lapangan, garis tengah, garis daerah serang adalah $3 \mathrm{~m}$ (daerah depan). Garis batas itu diberi tanda batas dengan menggunakan tali, kayu, cat/kapur, kertas yang lebarnya tidak lebih dari $5 \mathrm{~cm}$. lapangan permainan bola voli terbagi menjadi dua bagian sama besar yang masing-masing luasnya 9 x 9 meter. Di tengah lapangan dibatasi garis tengah yang membagi lapangan menjadi dua bagian sama besar. Masing-masing lapangan terdiri dari atas daerah serang dan daerah pertahanan. 
Daerah serang yaitu daerah yang dibatasi oleh garis tengah lapangan dengan garis serang yang luasnya $9 \times 3$ meter.

\section{Daerah Service}

Daerah service adalah daerah selebar 9 meter di belakang setiap garis akhir. Daerah ini dibatasi oleh dua garis pendek sepanjang $15 \mathrm{~cm}$ yang dibuat $20 \mathrm{~cm}$ di belakang garis akhir, sebagai kepanjangan dari garis samping. Kedua garis pendek tersebut sudah termasuk di dalam batas daerah service, perpanjangan daerah service adalah kebelakang sampai batas akhir daerah bebas.

\section{Antene Rod}

Di dalam pertandingan permainan bola voli yang sifatnya nasional maupun internasional, di atas batas samping jaring dipasang tongkat atau rod yang menonjol ke atas setinggi $80 \mathrm{~cm}$ dari tepi jaring atau bibir net. Tongkat itu terbuat dari bahan fibergelas dengan ukuran panjang $180 \mathrm{~cm}$ dengan diberi warna kontras.

\section{Bola}

Bola harus bulat terbuat dari kulit yang lentur atau terbuat dari kulit sintetis yang bagian dalamnya dari karet atau bahan yang sejenis. Warna bola harus satu warna atau kombinasi dari beberapa warna. Bahan kulit sintetis dan kombinasi warna pada bola dipergunakan pada pertandingan resmi internasional harus sesuai dengan standar FIVB.

Keliling bola $64-67 \mathrm{~cm}$ dan beratnya 260 - 280 grm, tekanan didalam bola harus $0,39-0$, $325 \mathrm{~kg} / \mathrm{cm} 2$ (4,26 - 4,61 Psi) (294,3 - 318,82 mbar/hpa.

\section{Net}

Jaring untuk permainan bola voli berukuran tidak lebih dari 9,50 meter dan lebar tidak lebih dari 1,00 meter dengan petak-petak atau mata jaring berukuran $10 \times 10 \mathrm{~cm}$, tinggi net untuk putra 2,43 meter dan untuk putri 2,24 meter, tepian atas terdapat pita putih selebar $5 \mathrm{~cm}$.

\section{Jumlah Pemain}

Jumlah pemain dalam lapangan permainan sebanyak 6 orang setiap regu dan ditambah 5 orang sebagai pemain cadangan dan satu orang pemain libero. Satu tim maksimal terdiri dari 
12 pemain, saru coach, satu sistem coach, satu trainer, dan satu dokter medis, kecuali libero, satu dari para pemain adalah kapten tim, dia harus diberi tanda dalam score sheet.

\section{Pergeseran Pemain}

Jika regu penerima servis berhasil mematikan bola di lapangan lawan, maka permain bergeser satu posisi searah jarum jam (misalnya : posisi satu ke posisi enam, posisi enam ke posisi lima, posisi lima ke posisi empat, dan seterusnya)

\section{Game/Set}

Permainan ditentukan dengan game/set. Regu yang memperoleh/ mengumpulkan angka 25 terlebih dahulu adalah pemenang dalam game tersebut. Jika kedudukkan angka $24-24$, maka dinyatakan jus (deuce) dan regu yang memperoleh selisih dua angka terlebih dahulu adalah pemenangnya.

Kemenangan regu bola voli ditentukan dengan dua sistem:

a. Sistem Two Winning Set yaitu setiap regu dikatakan menang bila telah memenangkan dua set.

b. Sistem Three Winning Set yaitu regu dikatakan menanng bila memenangkan tiga set.

9. Memainkan Bola

a. Suatu regu berhak memukul / memainkan bola maksimal 3 kali (disamping blok)

b. Seorang permain boleh memukul / memainkan bola dua kali berturut - turut (kecuali memblok / membendung)

c. Permain diperbolehkan memainkan bola menggunakan seluruh bagian tubuh (misalnya : kaki, kepala) dengan catatan pantulan bola sempurna / tidak berhenti.

d. Dua atau tiga permain boleh memukul bola pada saat yang sama (serentak)dan hal itu di hitung sebagai dua atau tiga kali pukulan (kecuali membendung)

e. Jika dua atau tiga permain menjangkau bola tetapi hanya satu permain yang memukulnya maka dihitung satu pukulan

10. Permainan Dekat Net 
a. Seorang pembendung (bloker) boleh menyentuh bola di daerah lawan, asal tidak menggangu permain lawan (menyentuh bola sebelum dipukul lawan)

b. Setelah melakukan serangan (smash) tangan boleh melewati net / masuk ke daerah lawan

c. Boleh melewati ruang permain lawan di bawah net, asalkan tidak mengganggu permain lawan

d. Tidak noleh menyentuh / menginjak garis tengah

e. Bagian dari badan tidak boleh menyentuh lapangn lawaN

\section{Bola Keluar}

Bola dinyatakan keluar apabila :

a. Jatuh seluruhnya di sisi luar garis - garis batas lapangan

b. Menyentuh bola diluar lapangan

c. Menyentuh antena, tali, tiang atau net di luar batas antenna

12. Kesalahan - Kesalahan Pada Saat Bermain

a. Pemain menyentuh net atau melewati garis batas tengah lapangan lawan.

b. Tidak boleh melempar ataupun menangkap bola. Bola volley harus di pantulkan tanpa mengenai dasar lapangan.

c. Bola yang dipantulkan keluar dari lapangan belum dihitung sebagai out sebelum menyentuh permukaan lapangan.

d. Pada sat servis bola yang melewati lapangan dihitung sebagai poin bagi lawan, begitu juga sebaliknya penerima servis lawan yang membuat bola keluar dihitung sebagai poin bagi lawan.

e. Seluruh pemain harus berada di dalam lapangan pada saat serve dilakukan.

f. Pemain melakukan spike di atas lapangan lawan.

g. Seluruh bagian tubuh legal untuk memantulkan bola kecuali dengan cara menendang. 
h. Para pemain dan lawan mengenai net 2 kali pada saat memainkan bola dihitung sebagai double faults. Setiap team diwajibkan bertukar sisi lapangan pada saat setiap babak berakir. Dan apabila dilakukan babak penetuan (set ke 3) maka tim yang memiliki nilai terendah boleh meminta bertukar lapangan sesaat setelah tim lawan mencapai angka 13. Time out dilakukan hanya 1 kali dalam setiap babak dan berlangsung hanya 1 menit. Diluar dari aturan yang tertera disini, peraturan permainan mengikuti peraturan international.

13. Kesalahan - kesalahan pada saat servis

a. Bola servis menyentuh antenna

b. Pada saat memukul bola, kaki menginjak garis lapangan

c. Bola tidak dilambungkan terlebih dahulu

d. Bola dipukul keluar lapangan

e. Mengulur - ulurkan waktu / memperlambat permainan

f. Servis dari luar garis perpanjangan lapangan.

2. Teknik Dasar Permainan Bola Voli

1. Servis Tennis (Tennis Service)

a. Sikap pemulaan

Berdiri dengan kaki kiri ke depan, bola di pegang dengan dua tangan (tangan kiri menyangga bola dan tangan kanan memengang bagian atas).

b. Pelaksanaan

Bola dilambungkan dengan tangan kiri ke atas kurang lebih meter di atas kepala. Tangan kanan segera ditarik kebelakang atas kepala, telapak tangan menghadap ke depan. Kemudian bola dipukul dengan tangan pada bagian belakang atas, dibantu dengan lecutan pergelangan tangan, sehingga jalannya bola top spin (berputar ke depan). Gerakan diakhiri dengan melangkahkan kaki ke depan. 


\section{Teknik Dasar Smash}

Smash adalah memukul bola yang dilakukan di atas net dengan kuat dan keras hingga bola jatuh menukik di lapangan lawan, dan sulit untuk dikembalikkan /diterima. Smash sendiri merupakan rangkaian gerakkan yang komplek terdiri dari empat tahap sehingga diperlukan koordinasi gerakkan yang baik untuk melakukannya. Keempat tahapan smash tersebut adalah:

1. Langkah awalan

Diawali dengan sikap berdiri agak serong, dengan jarak 2 - 4 m dari net. Langkahkan kaki ke depan kaki kiri diikuti dengan kaki kanan dan langkah panjang kaki kiri dengan posisi terakhir kaki hampir sejajar untuk ditekuk/ posisi badan merendah.

\section{Tolakan/ tumpuan}

Sambil merendahkan badan kedua lengan di belakang badan, segera lakukan tolakan ke atas dengan kuat sambil mengayun lengan ke depan atas, tangan kanan berada di samping atas kepala.

\section{Perkenalan bola}

Perkenalan/pukulan bola dilakukan saat mencapai titik tertinggi dari loncatan, jarak bola satu jangkauan tangan, posisi bola tepat di depan atas kepala. Lakukan pukulan di bagian atas belakang bola dengan telapak tangan terbuka disertai dengan lecutan tangan hingga menghasilkan bola top spin.

\section{Pendaratan.}

Pendaratan dengan kedua kaki sejajar disertai gerakan ngeper pada kedua lutut, dan tetep menjaga keseimbangan untuk segera kembali pada sikap siap normal.

4. Teknik Dasar Memblok (Membendung) 
Merupakan salah satu teknik bertahan yang dilakukan di atas net, dengan cara melompat sambil menjulurkan kedua tangan untuk menahan smash lawan.

Ada dua teknik blok yaitu :

\section{Block aktif}

Di mana saat melakukan block kedua tangan dengan kuat menahan bola dan saat perkenaan tangan tangan aktif menekan bola ke bawah.

\section{Block pasif}

Dimana saat melakukan tangan dijulurkan kdekat net tanpa disertai gerakkan apapun. Cara ini dilakukan oleh pemain dengan postur tubuh pendek dengan keterbatasan jangkauan tangan.

Block yang baik sangat efektif untuk melakukan pertahanan smash lawan kkarena dapat dilakukan secara perorangan maupun berpasangan dua atau tiga pemain sekaligus.

Teknik melakukan block / bendungan.

1. Sikap awal

Berdiri menghadap net kaki sejajar kedua tangan di depan dada, lutut ditekuk badan agak condong ke depan. Pandangan fokus ke arah bola dan pergerakkan smasher lawan.

\section{Pelaksanaan}

Lakukan tolakan dengan kuat kedua tangan dijulurkan ke atas net selebar bahu telapak jarijari terbuka. Arahkan tangan ke daerah perkiraan lintasan bola/smash lawan. Saat perkenaan jari - jari ditegangkan agar kuat menahan smash lawan.

\section{Gerakan akhir}

Lakukan pendaratan dengan kedua kaki disertai gerakan ngeper pada lutut, seimbangan tetap terjaga dan segera mengambil posisi siap kembali pada permainan. 


\section{BAB III}

\section{PENUTUP}

\section{KESIMPULAN}

Dalam pemainan dan olahraga bola voli dapat membuat tubuh menjadi sehat karena mengeluarkan keringat dari tubuh. Bola voli juga dapat mehilangkan atau menghidari kejenuhan siswa / siswi dalam mempelajari teknik dasar pemain bola voli. Karena, pemainan dan olahraga bola voli mempunyai peraturan yang dimodifikasi yang membuat siswa / siswi dapat mehilangkan atau menghindari kejenuhan ketika belajar atau memainkan permainan atau olahraga bola voli ini.

\section{DAFTAR PUSTAKA}

https://proposaldanmakalah.blogspot.com/2017/02/makalah-olahraga-bola-voli.html https://sule-epol.blogspot.com/2017/08/makalah-permainan-bola-voli.html https://ajiezaenulamry.blogspot.com/2015/02/makalah-tentang-permainan-bola-voli.html https://adrimoko.blogspot.com/2018/01/makalah-tentang-bola-voli.html 